\title{
FRONTLINE HEALTH PROVIDER'S PERSPECTIVE IN REDUCING CHILD DEATHS DUE TO MALNUTRITION IN A TRIBAL DISTRICT OF MAHARASHTRA: A QUALITATIVE STUDY
}

KEY WORDS: Malnutrition;

Frontline workers
Dr. Lalit Sankhe*

Dr. Chhaya

Rajguru

Dr. Monali

Kadam
Faculty, Department of Community Medicine, GGMC, Grant Government Medical College, Mumbai. *Corresponding Author

Faculty, Department of Community Medicine, GGMC, Grant Government Medical College, Mumbai.

Postgraduate student of Community Medicine, GGMC, Grant Government Medical College, Mumbai.

Background: Malnutrition is a complex problem with double burden of undernutrition and overweight. India is no exception to it but there is a higher level of malnutrition in tribal blocks and to curb this situation, various activities have been undertaken but the slow pace of decline in malnutrition is a concern. The role of frontline health workers is crucial in strengthening primary health care. They serve as the bridge between the formal government health-care system and the community. The present study helps to seek the perception of primary health care service providers and challenges faced by them in reducing child deaths due to malnutrition.

Method: A descriptive cross sectional qualitative study was conducted during August 2019 - February 2020 in three talukas of a tribal district. Focus group discussions (FGD) for each service providers Auxiliary Nurse midwife (ANM), Anganwadi worker (AWW) and Accredited Social Health activist (ASHA) were conducted. All the FGDs were audio recorded and transcripts were prepared, a thematic analysis framework was used for doing the analysis.

Results: Most of the service providers were aware regarding their roles and responsibilities in implementation of schemes/ services related to malnutrition. The important factors influencing their performance were superstitions, more reliance on health seeking from unqualified health care providers and faith healers, poor road connectivity, network issues, lack of refresher training, overburdening with work, poor incentives.

Conclusion: Specific training programs to tackle malnutrition along with frequent refresher training of the service providers, better infrastructure and human resources will help in achieving the desired results in future in dealing with child malnutrition.

\section{INTRODUCTION:}

Malnutrition remains an unsolved problem in the world. Most of the low and middle income countries are affected with overlapping forms of malnutrition ${ }^{1}$. Millions of children are suffering from various forms of malnutrition, stunting, wasting and overweight. The prevalence of malnutrition is still alarming, globally among the under 5 children according to the UNICEF March 2020 data, 144 million (21.3\%) are stunted, 47 million (6.9\%) show wasting, 38.3 million (5.6\%) are overweight ${ }^{2}$. According to WHO, one in four children born in South Asia is malnourished with $45 \%$ of deaths linked with under nutrition.

In India according to NFHS 4 (2015-16), among under 5 children, 38\% stunted (low height-for-age), $21 \%$ wasted (low weight-for-height), $36 \%$ are underweight (low weight-forage). Nutritional outcomes among children have been reported to be influenced by rural- urban differentials in the place of residence ${ }^{12}$. Malnutrition is higher in tribal children and $80 \%$ are undernourished living in eight states of Karnataka, Chhattisgarh, Gujarat, Jharkhand, Madhya Pradesh, Maharashtra, Rajasthan and Odisha. About $40 \%$ of under-five tribal children in India are stunted and $16 \%$ of them are severely stunted. In Maharashtra $34 \%$ under 5 children are stunted and one in every ten children is born with low weight ${ }^{2}$.

The most affected regions in Maharashtra are the tribal blocks. Particularly in Palghar district during 2016, more than 600 children died due to undernutrition ${ }^{4}$. The state then announced multiple measures to address child malnutrition in tribal dominated areas; District Specific Action Plan (DAP) was developed to tackle the issues related to child death due to malnutrition.

Malnutrition causes mortality, morbidity which is short term effects but may lead to long term effects like impairment of child's growth, cognition affecting the economic 246 development of future generation ${ }^{13}$. Presently most of the existing government schemes related to malnutrition are run by Integrated Child Development schemes (ICDS), Public Distribution System (PDS), Mid - Day Meal, Anganwadi services, Poshan Abhiyan ${ }^{14}$. With the above background, this study is undertaken to understand the perspective and challenges faced by the service providers and services given by them to combat malnutrition in tribal blocks of Maharashtra.

\section{Methodology:}

The study was planned to seek the perception of service providers, challenges faced and address the suggestion given by them to tackle the malnutrition in tribal blocks.

A Descriptive cross sectional qualitative study design was planned. A tribal district was selected for the study purpose. Multistage stratified purposive sampling technique was used. Among the 8 talukas, three talukas were selected on the basis of child health indicators and implementation of District Action Plan (DAP). Also the selected tribal blocks have more than $40 \%$ tribal population. The sub-district hospital catering above talukas was identified and all the Primary Health centres (PHC) under them were selected. Two sub-centers under the PHCs were chosen on the basis of their performance. The service providers ANM, AWW and ASHA catering to the chosen sub-centers were the study participants and the data was collected by conducting focus group discussion (FGDs).

Focus group discussions were conducted at PHC's by a team of four, which included facilitator, two Recorders, and an observer. Consent was taken from all the participants. Total 9 FGDs were conducted, I FGD for each service provider in each taluka. In the FGDs total number of participants for ANM, AWW and ASHA were 24, 26 and 27 respectively. FGDs were audio recorded and transcribed. Ethical clearance for conducting the study was obtained from Institutional ethics 
committee.

The transcribed text of FGDs were noted by field investigators in regional language and later translated into English. Data was analyzed manually using thematic analysis framework. Four themes were identified which are as follows: Awareness and Training, Activities performed, Challenges, and Suggestions. The information from recorded FGDs were transcribed in alignment with study objectives and coded with the help of field notes, and verbatim was prepared for each FGD. The results were summarized and tabulated according to primary health care level service provider categories. The results were presented in a semi-quantitative qualifiers form ${ }^{16}$.

\section{RESULTS AND DISCUSSION:}

The four themes were identified from the data collected from service providers ANM, AWW and ASHA respectively. They are awareness and training, activities performed, challenges and suggestions which are discussed according to the theme below:

Table 1: Theme 1: Awareness and training about the child malnutrition and schemes related to it:

\section{Service Awareness and perception about the various} provide schemes for malnutrition

rs

ANM $\quad$ Reduction in malnutrition among under 5 children $-50-74 \%$

Fortified food, nutritional requirement of pregnant women and malnourished child- $\geq 90 \%$

Identify SAM,MAM, high risk mothers- $\geq 90 \%$

Knowledge about VCTC, NRC, causes of

malnutrition $-\geq 90 \%$

Dhanya Mahotsav- < 25\%

HBNC, IMNCI and Partogram \& No specific

training for malnutrition $-50-74 \%$

AWW $\quad$ Malnutrition was decreasing in their area- 50-74\% Knowledge about VCTC, NRC- 75-89\%

Causes of malnutrition- $50-74 \%$

Fortified food - $\geq 90 \%$

Identification of SAM and MAM children, high risk mothers- $50-74 \%$

Anna Mahotsav- $<25 \%$

No specific training for malnutrition- $50-74 \%$

\begin{tabular}{l|l}
\hline ASHA & Nutritional condition of the children was
\end{tabular}

improving-50-74\%

VCTC, NRC- $\geq 90 \%$

Causes of malnutrition-25-49\%

Fortified food $\geq 90 \%$

Methods of identification of SAM and MAM

children- $\geq 90 \%$

Identify High risk mothers-75-89\%

HBNC \& IYCF guidelines- $\geq 90 \%$

Not received specific training for malnutrition $\geq$ $90 \%$

According to the majority of the service providers, most common causes for malnutrition were early marriages, poor immunity and superstitions.

"People follow many false beliefs if child suffers from breathlessness (in local language termed as 'daba zala'), they take the child to "Bhagats" were some mantras are enchanted by them." (participant from ASHA FGD)

Almost all of the ANM and ASHA were aware about malnutrition related government schemes for pregnant, lactating mothers and malnourished children while only the majority of AWW knew about them. The participants mentioned few of the malnutrition schemes such as Amrut Aahar Yojana, Poshan Abhiyan, and supplementary food provided in Anganwadi, Take Home ration, National Rehabilitation Centre (NRC).
"At anganwadi for pregnant mothers, under Amrut AaharYojana we provide one time meal which is additional food for her." (participant from ANM FGD)

Very few of the primary health care service providers had knowledge about the Dhanya Mahotasav and Anna din.

We found that ANM, AWW and ASHA were aware of the child malnutrition situation in their blocks and agreed to gradual improvement in the prevalence of malnutrition ${ }^{4}$.

The training conducted for all the service providers is not on a regular basis and there is a long gap between two refresher trainings conducted. Also there is no separate training session conducted related to malnutrition. In the study conducted by Dongre et al (2008), there was no regular training sessions conducted for the AWW in tribal blocks ${ }^{9}$. Regular training sessions focusing on child malnutrition is the need of the hour in further improving the scenario.

Table 2: Theme 2: Activities Performed By The Primary Level Service Providers

\begin{tabular}{|l|l|}
\hline $\begin{array}{l}\text { Service } \\
\text { providers }\end{array}$ & Activities performed \\
\hline ANM & $\begin{array}{l}\text { Growth monitoring- } \geq 90 \% \\
\text { Distribution of Iron, folic acid tablets to } \\
\text { adolescent girls- } \geq 90 \% \\
\text { Create awareness among pregnant women } \\
\text { adolescent girls about personal hygiene, } \\
\text { nutrition- } 25 \text { - 49\% } \\
\text { Encourage parents of SAM/MAM children to } \\
\text { admit them at NRC, regular follow up- } \\
\geq 90 \%\end{array}$ \\
\hline AWW & $\begin{array}{l}\text { Supplementary food, Take home ration , Mata } \\
\text { Baitaks, Kishori Baitak- 50-74\% } \\
\text { Growth monitoring- 50-74\% } \\
\text { Encourage parents of SAM/MAM children to } \\
\text { admit them at NRC, regular follow up- } \\
75-89 \%\end{array}$ \\
\hline ASHA & $\begin{array}{l}\text { Measure Hemoglobin of adolescent girls- } \geq 90 \% \\
\text { Sanitary napkins- } \geq 90 \% \\
\text { Advice pregnant women for early registration } \\
\text { and checkup- } \geq 90 \% \\
\text { Accompany Pregnant women to the hospitals- } \geq \\
90 \% \\
\text { Refer sick children to PHC with referral slip and } \\
\text { accompany them to RH- } \geq 90 \% \\
\text { Regular visit to SAM/MAM child post discharge } \\
\text { till } 6 \text { months- <25\% } \\
\text { Celebration of Village health day and Nutrition } \\
\text { day on Immunization day- <25\% }\end{array}$ \\
\hline
\end{tabular}

Almost all the AWW actively participated in preparation of supplementary nutrition and distribution of take home ration (THR).

"THR provided at Anganwadi, are shared by all the family members" (participant from AWW FGD)

Most of the AWWs motivated parents of malnourished child to admit them in Nutritional Rehabilitation center (NRC) while majority of them conducted "Mata Baitak" and "Kishori Baitak"

Almost all the ASHAs organized a camp in schools for hemoglobin estimation, distributed sanitary napkins to adolescent girls, referrals to PHCs but very few of them continued home visits to SAM/MAM children for 6 months after discharge from NRC.

In this study it was reported that benefits provided to the beneficiaries were shared by the family members and thus got diluted and the concerned child is not benefited. Birdi TJ et al (2014) had similar findings in their study ${ }^{14}$. It is therefore 
important to design interventions that are family centric and not child centric.

The community participation is encouraged in the form of self-help group "Bachat Gat" which provides meals to the SAM/MAM children ${ }^{8}$. In this study, the service providers faced the issue of unavailability of timely funds and irregular supply of take home ration. A robust monitoring system to assure timely availability of funds and resources will not hamper the services providers at the health centers.

Table 3: Theme 3: Challenges Faced By The Primary Level Service Providers:

\begin{tabular}{|l|l|}
\hline $\begin{array}{l}\text { Service } \\
\text { providers }\end{array}$ & Challenges \\
\hline ANM & $\begin{array}{l}\text { Poor road connectivity- } \geq 90 \% \\
\text { Superstition - "Bhagats" } \geq 90 \% \\
\text { Overburdened with offline and online work } \\
\text { activities - } \geq 90 \%\end{array}$ \\
\hline AWW & $\begin{array}{l}\text { Religious beliefs, traditional practices, faith } \\
\text { healers- 50-74\% } \\
\text { Parents have to face loss of daily wages - } \geq \\
90 \%\end{array}$ \\
\hline ASHA & $\begin{array}{l}\text { Religious beliefs, traditional practices, } \\
\text { "Bhagats"- } \geq 90 \% \\
\text { Family life gets affected as no holidays and no } \\
\text { fixed duty hours- } \geq 90 \% \\
\text { Road connectivity } \\
\text { Network issues for online record uploading }\end{array}$ \\
\hline
\end{tabular}

Almost all of the service providers faced the issues of superstition, poor road connectivity, network issues and heavy work load, shortage of infrastructure.

"Have to go walking from one pada to the other in difficult to reach areas because roads are poor" (participant from ANM FGD).

All the service providers mentioned that there is heavy workload as they have to do dual work online data entry and maintaining the registers as well as field work which leads to long working hours.

But due to superstition, poor health seeking behavior was present in the community and so the malnourished child was not taken to the health facility. These findings were similar to the study conducted by Dongre et al (2008) in tribal district of Maharashtra ${ }^{9}$.This can be changed by involving local leaders and faith healers in creating awareness among the people. Improving educational status in the community also might help to eradicate the superstitious and early marriage practices ${ }^{17}$.

The service providers ANM, ASHA and AWW are over burdened by the online entry, paperwork and the field work. This leads to work stress among them. The frontline workers, especially ASHA, were dissatisfied with incentives given to them compared to the workload. Deshpande $\mathrm{S}$ et al (2019) and Guha, I et al (2020) noted similar findings in their study for analyzing the challenges faced by ASHA in tribal region ${ }^{15,19}$.

Table 4: Theme 4: Suggestions Given By The Primary Level Service Providers:

\begin{tabular}{|l|l|}
\hline $\begin{array}{l}\text { Service } \\
\text { providers }\end{array}$ & Suggestions \\
\hline ANM & $\begin{array}{l}\text { Frequent training }-\geq 90 \% \\
\text { Filling of vacant posts- } \geq 90 \% \\
\text { Facility of transportation for difficult to reach } \\
\text { areas- } \geq 90 \%\end{array}$ \\
\hline AWW & $\begin{array}{l}\text { Increment in incentives- } \geq 90 \% \\
\text { Availability of vehicle for patients transport- } \\
\geq 90 \% \\
\text { Refresher trainings- } \geq 90 \%\end{array}$ \\
\hline
\end{tabular}

\begin{tabular}{|l|l|}
\hline ASHA & Increase in honorarium \\
& Weighing scale in kits \\
& Availability of nebulizer \\
& Refresher training \\
& Regular provision of supply of medicines as \\
& they have to spend money from their pocket \\
& Data entry operator for online uploading of \\
records
\end{tabular}

Majority of the service provider's suggested for frequent training, availability of transportation, regular supply of medicines and increment in the incentives.

"We need frequent training at about 3 - 6 months, so that we don't forget whatever we have been taught in the training." (participant from ASHA FGD)

The vacant posts especially for ANM were not filled and similar finding were reported in the study conducted by Meena S et al (2020) ${ }^{20}$. Almost all the ANM recommended the filling of vacant posts of ANM at various health centers. Provision of quality medical care in tribal blocks can be achieved by appropriate allocation of manpower with suitable incentives.

Following flow diagram represents the Major Factors influencing service provider's performance:Figure 1

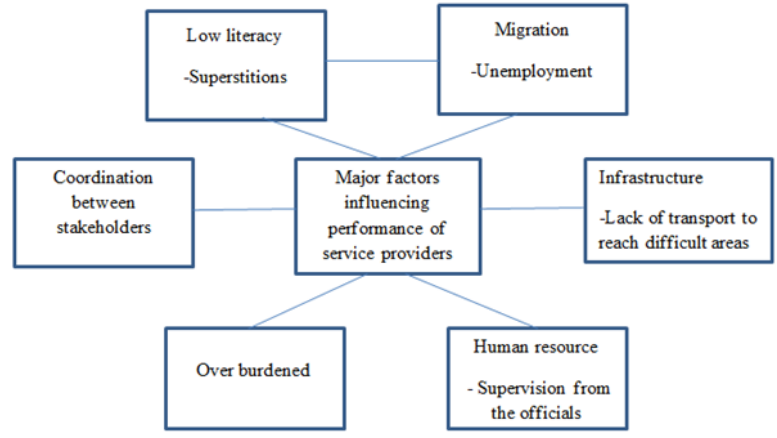

\section{CONCLUSION:}

Quality training programs and more efforts regarding sensitizing and motivating ANM, AWW and ASHAs may be helpful for improving their performance. Provision of fair monetary incentives and regularization of incentives can be effective in motivating ASHAs and AWW for participating efficiently in health-care delivery system. Additionally it was brought to notice by the service providers that low female literacy among the beneficiaries leads to poor health seeking behavior and poor child bearing and rearing practices. Improving the level of education will not only improve the health seeking behavior but also generate livelihood opportunities in the tribal blocks.

\section{REFERENCES:}

1. Popkin, B. M., Corvalan, C., \& Grummer-Strawn, L. M. (2020). Dynamics of the double burden of malnutrition and the changing nutrition reality. The Lancet 395(10217), 65-74.

2. UNICEF 2020. Retrieved from https://data.unicef.org/topic/nutrition/ malnutrition/,https://www.unicef.org/india/what-we-do/tribal-nutrition

3. National family health survey 4 (2015-16) NFHS 4. Retrieved from http://rchiips.org/nfhs/factsheet_nfhs-4.shtml

4. Ghosh, S., \& Varerkar, S. A. (2019). Undernutrition among tribal children in Palghar district, Maharashtra, India.PloS one, 14(2), e0212560.

5. Acharya, S. (2018). How AWW, ANM and Asha help in development of the ICDS to tackle malnutition and health issue for a better India. International Journal of Advanced Research in Management and Social Sciences, 7(8), 18-50.

6. Jain, R., \& Narnaware, P. (2020). Application of Systems Thinking to Dent Child Malnutrition:A Palghar District, India Case Study.Millennial Asia, 1 (1), 79-98.

7. Shrivastava, P. (2012). Evaluation of trained Accredited Social Health Activist (ASHA) workers regarding their knowledge, attitude and practices about child health.

8. Feruglio, F., \& Nisbett, N. (2018). The challenges of institutionalizing community-level social accountability mechanisms for health and nutrition: a qualitative study in Odisha, India. BMC health services research, 18(1), 1-13.

9. Dongre, A. R., Deshmukh, P. R., \& Garg, B. S. (2008). Perceived responsibilities of Anganwadi workers and malnutrition in rural Wardha. Onlinae Journal of Health and Allied Sciences, 7(1)

10. Saprii, L., Richards, E., Kokho, P., \& Theobald, S. (2015). Community health workers in rural India: analysing the opportunities and challenges 
Accredited Social Health Activists (ASHAs) face in realising their multiple roles. Human resources for health, 13(1), 1-13.

11. Chaand, I., Horo, M., Nair, M., Harshana, A., Mahajan, R., Kashyap, V., ... \& Dasgupta, R. (2019). Malnutrition in Chakradharpur, Jharkhand: an anthropological study of perceptions and care practices from India. $B M C$ nutrition, 5(1), 1-12.

12. Kumar, A., \& Kumari, D. (2014). Decomposing the rural-urban differentials in childhood malnutrition in India, 1992-2006. Asian Population Studies, 10(2), 144-162.

13. Poh, B. K., Rojroonwasinkul, N., Le Nyugen, B. K., Budiman, B., Ng, L. O., Soonthorndhada, K., ... \& Parikh, P. (2013). Relationship between anthropometric indicators and cognitive performance in Southeast Asian school-aged children. British Journal of Nutrition, 110 (S3), S57-S64.

14. Birdi, T. J., Joshi, S., Kotian, S., \& Shah, S. (2014). Possible causes of malnutrition in Melghat, a tribal region of Maharashtra, India. Global journal of health science, $6(5), 164$

15. Guha, I., Raut, A. V., Maliye, C. H., Mehendale, A. M., \& Garg, B. S. (2018). Qualitative Assessment of Accredited Social Health Activists (ASHA) Regarding their roles and responsibilities and factors influencing their performance in selected villages ofWardha. International Journal of Advanced Medical and Health Research, 5(1),21.

16. Nujum, Z. T., Remadevi, S., Jose, R., Nirmala, C., Rajmohanan, K., Indu, P. S., \& Nair, S. M. (2013). Evaluation of coverage and compliance to Mass drug administration (MDA) for lymphatic filariasis elimination-A qualitative study. Acad MedJIndia, 1 .

17. Raj, A., Saggurti, N., Winter, M., Labonte, A., Decker, M. R., Balaiah, D., \& Silverman, J. G. (2010). The effect of maternal child marriage on morbidity and mortality of children under 5 in India: cross sectional study of a nationally representative sample. $B m j, 340$.

18. Sonowal, C.J. (2010). Factors affecting the nutritional health of tribal children in Maharashtra. Studies on Ethno-Medicine, 4(1), 21-36.

19. Deshpande, S., Barsha Gadapani, P., \& Manapurath, R. M. Analyzing the challenges and demotivating factors faced by accredited social health activist workers in tribal India in implementing their roles..

20. Meena, S., Rathore, M., Kumawat, P., \& Singh, A. (2020). Challenges Faced by ASHAs during their Field Works: A Cross Sectional Observational Study in Rural Area of Jaipur, Rajasthan. International Journal of Medicine and Public Health, 10(3). 